\title{
Unsteady Stokes Flow of Viscous Fluid between Two Parallel Porous Plates \\ Ganesh S ${ }^{1}$, Krishnambal S ${ }^{2}$ \\ ${ }^{1} \mathrm{HOD}$, Department of Mathematics, Sathyabama University,Chennai \\ sganesh19@yahoo.com \\ ${ }^{2}$ Professor, Department of Mathematics, Anna University, Chennai \\ Email : ambal@annauniv.edu
}

\section{INTRODUCTION}

The two dimensional steady state laminar flow in channels with porous walls has numerous applications in various branches of Engineering and Technology such as boundary layer control and transpiration cooling problems. It plays an important role in the study of problems which involve diffusion phenomena in a flowing gas stream.

Berman(1953) was the first researcher who studied the problem of steady flow of an incompressible viscous fluid through a porous channel with rectangular crosssection, when the Reynolds number is low. He obtained a perturbation solution assuming normal wall velocities to be equal. Then Sellars(1955) extended the problem studied by Berman when the Reynolds number is very high. Afterwards Yuan(1956) and Terill(1964) studind the problem for various values of suction and Reynolds numbers. Terill and Shrestha(196? analysed the same problem, assuming different norma velocities at the walls.

Drake(1965) has considered the flow of an incompressible viscous fluid in a long channel of rectangular section due to a periodic pressure gradient. Bagchi(1966) has studied the unsteady flow of visc elastic Maxwell fluid with transient pressure gradie through a rectangular channel.

In this paper, we consider the unsteady flow of an incompressible viscous fluid between two parallel porous plates when there is a periodic injection at the lower plate and suction at the upper plate.

\section{Formulation of the problem:}

Consider the flow of incompressible fluid through two parallel porous plates $y=0$ and $y=h$ along the direction of $x$-axis. Assume that there is a periodic injection of velocity $v_{1} e^{i n t}$ at the lower plate and periodic suction of velocity $v_{2} e^{i \text { it }}$ at the upper plate. Hence we choose the velocity vector $(\overline{\mathrm{q}})$ and the pressure in the form

$$
\begin{aligned}
& \overline{\mathrm{q}}=\left[\mathrm{u}(\mathrm{x}, \mathrm{y})_{i}+\mathrm{v}(\mathrm{x}, \mathrm{y}) \hat{j}\right] \mathrm{e}^{\mathrm{iwt}} \text { and } \mathrm{P}(\mathrm{x}, \mathrm{y})=\mathrm{p}(\mathrm{x}, \mathrm{y}) \mathrm{e}^{\mathrm{iwt}} \text {, } \\
& \text { where } \mathrm{u}(\mathrm{x}, \mathrm{y}) \text { and } \mathrm{v}(\mathrm{x}, \mathrm{y}) \text { are the velocity } \\
& \text { components of the flow along the coordinate } \\
& \text { directions }(\mathrm{x}, \mathrm{y}) \text { respectively. }
\end{aligned}
$$

Equation of continuity and equations of motion are

$$
\begin{gathered}
\frac{\partial u}{\partial x}+\frac{\partial v}{\partial y}=0 \\
\rho \frac{\partial u}{\partial t}=-\frac{\partial p}{\partial x}+\mu\left(\frac{\partial^{2} u}{\partial x^{2}}+\frac{\partial^{2} u}{\partial y^{2}}\right) \\
\text { and } \rho \frac{\partial v}{\partial t}=-\frac{\partial p}{\partial y}+\mu\left(\frac{\partial^{2} v}{\partial x^{2}}+\frac{\partial^{2} v}{\partial y^{2}}\right)
\end{gathered}
$$

Represents the coefficient of viscosity and the density of the fluid. The boundary conditions of the problem are

$$
\begin{aligned}
& \mathrm{u}(\mathrm{x}, 0)=0, \mathrm{u}(\mathrm{x}, \mathrm{h})=0 \\
& \mathrm{v}(\mathrm{x}, 0)=\mathrm{v}_{1}, \mathrm{v}(\mathrm{x}, \mathrm{h})=\mathrm{v}_{2}
\end{aligned}
$$

Where $\mathrm{h}$ is the distance between the two parallel porous plates and $v_{1}$ and $v_{2}$ are constants. We introduce the stream function $(x, y)$ through

$$
\mathrm{u}(\mathrm{x}, \mathrm{y})=\frac{\partial \psi}{\partial \mathrm{y}} \text { and } \mathrm{v}(\mathrm{x}, \mathrm{y})=-\frac{\partial \psi}{\partial \mathrm{x}}
$$

so that the equation of continuity (1) is satisfied. Equations (2) and (3) give

rise to

$$
\begin{aligned}
& \rho \mathrm{i} \omega \mathrm{u} \mathrm{e}^{\mathrm{iet}}=-\mathrm{e}^{\mathrm{iet}} \frac{\partial \mathrm{p}}{\partial \mathrm{x}}+\mu\left(\nabla^{2} \psi\right) \mathrm{e}^{\mathrm{iet}} \\
& \rho i \omega \frac{\partial \psi}{\partial y}=-\frac{\partial p}{\partial x}+\mu \frac{\partial}{\partial y}\left(\nabla^{2} \psi\right) \\
& \rho i \omega v e^{i e t}=-\frac{\partial p}{\partial y}-\mu \frac{\partial}{\partial x}\left(\nabla^{2} \psi\right) \\
& \text { and } \quad-\rho i \omega \frac{\partial \psi}{\partial x}=-\frac{\partial p}{\partial y}-\mu \frac{\partial}{\partial x}\left(\nabla^{2} \psi\right)
\end{aligned}
$$

Partially differentiating (6) w.r.t., 'y' we get

$$
\frac{\partial^{2} p}{\partial y \partial x}=\mu \frac{\partial^{2}}{\partial y^{2}}\left(\nabla^{2} \psi\right)-i \rho \omega \frac{\partial^{2} \psi}{\partial y^{2}}
$$

Partially differentiating (7) w.r.t., ' $x$ ' we get

$\frac{\partial^{2} p}{\partial x \partial y}=i \rho \omega \frac{\partial^{2} \psi}{\partial x^{2}}-\mu \frac{\partial^{2}}{\partial x^{2}}\left(\nabla^{2} \psi\right)$ 
Eliminating the pressure $p$ from the equations (8) and (9) we get

$$
\begin{gathered}
\mu\left(\frac{\partial^{2}}{\partial \mathrm{x}^{2}}+\frac{\partial^{2}}{\partial \mathrm{y}^{2}}\right) \nabla^{2} \psi-i \rho \omega\left(\frac{\partial^{2} \psi}{\partial \mathrm{x}^{2}}+\frac{\partial^{2} \psi}{\partial \mathrm{y}^{2}}\right)=0 \\
\text { i.e., } \quad\left(\mu \nabla^{2}-i \rho \omega\right) \nabla^{2} \psi=0
\end{gathered}
$$

We introduce $f(\eta)$ as follows:

$\psi=h\left(\frac{\mathrm{u}_{0}}{\mathrm{a}}-\frac{\mathrm{v}_{2} \mathrm{x}}{\mathrm{h}}\right) \mathrm{f}(\eta)$

where $\quad \eta=\frac{\mathrm{y}}{\mathrm{h}}, \quad \mathrm{a}=1-\frac{\mathrm{v}_{1}}{\mathrm{v}_{2}}, \quad 0 \leq\left|\mathrm{v}_{1}\right| \leq\left|\mathrm{v}_{2}\right|$

and $u_{0}$ is the average entrance velocity.

$$
\therefore \text { Equation (10) can be rewritten as }
$$

$\left(D^{2}-\frac{i \rho \omega h^{2}}{\mu}\right) D^{2} f(\eta)=0$

where $D^{2}=\frac{d^{2}}{d \eta^{2}}$.

The boundary conditions on $f(\eta)$ are given by

$f(0)=1-a, f(1)=1$ and $f^{\prime}(0)=f^{\prime}(1)=0$

Solving equation (12),

we get $\quad f(\eta)=c_{1}+c_{2} \eta+c_{3} e^{\alpha h \eta}+c_{4} e^{-a h \eta}$

Applying the boundary conditions on $\mathrm{f}(\eta)$ and solving, the values of the arbitrary constants are obtained as follows.

$$
\begin{aligned}
c_{1}=1-a & -\frac{a\left(e^{\alpha h}+e^{-\alpha h}-2\right)}{4+e^{\alpha h}(\alpha h-2)-e^{-\alpha h}(2+\alpha h)} \\
c_{2} & =\frac{\alpha h a\left(e^{\alpha h}-e^{-\alpha h}\right)}{4+e^{\alpha h}(\alpha h-2)-e^{-\alpha h}(\alpha h+2)} \\
c_{3} & =\frac{a\left(e^{-\alpha h}-1\right)}{4+e^{\alpha h}(\alpha h-2)-e^{-\alpha h}(\alpha h+2)} \\
c_{4} & =\frac{a\left(e^{\alpha h}-1\right)}{4+e^{\alpha h}(\alpha h-2)-e^{-\alpha h}(\alpha h+2)}
\end{aligned}
$$

Substituting the value of $f(\eta)$ in (11), the stream function is calculated. Using the expression for $\psi$ and equation (5) the velocity components are determined.

$$
\begin{aligned}
\mathrm{u}=\mathrm{u}(\mathrm{x}, \mathrm{y}) \mathrm{e}^{\mathrm{i} \omega t} & \\
& =\left(\frac{u o}{a}-\frac{v_{2} x}{h}\right)\left(\mathrm{c}_{2}+\mathrm{c}_{3} \alpha h \mathrm{e}^{\alpha \mathrm{y}}-\mathrm{c}_{4} \alpha \mathrm{he}^{-\alpha \mathrm{y}}\right) \mathrm{e}^{\mathrm{i} \omega t} \\
& =\left(\frac{u o}{a}-\frac{v_{2} x}{h}\right) \frac{\left(e^{\alpha h}-e^{-\alpha(j-h)}-e^{-\alpha h}+e^{\alpha(j-h)}+e^{-\alpha y}-e^{\alpha y}\right)}{4+e^{\alpha h}(\alpha h-2)-e^{-\alpha i}(\alpha h+2)}
\end{aligned}
$$

$$
\begin{aligned}
& \mathrm{v}=\mathrm{v}(\mathrm{x}, \mathrm{y}) \mathrm{e}^{\mathrm{i} e \mathrm{t} t} \\
& v=v_{2}\left(c_{1}+c_{2} \frac{y}{h}+c_{3} e^{a y}+c_{4} e^{-a y}\right) e^{i \omega t}
\end{aligned}
$$

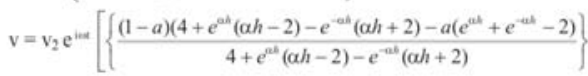

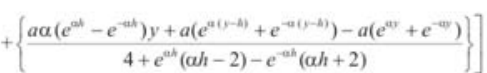

Pressure distribution:

From equations (6), (7) and (11) we have

$$
\begin{aligned}
& \text { i } \rho \omega\left(\frac{u o}{a}-\frac{v_{2} x}{h}\right) f(\eta)=-\frac{\partial p}{\partial x}+\frac{\mu}{h^{2}}\left(\frac{u o}{a}-\frac{v_{2} x}{h}\right) f^{\prime \prime \prime}(\eta) \\
& i \rho \omega v_{2} f(\eta)=-\frac{1}{h} \frac{\partial p}{\partial \eta}+\frac{\mu v_{2}}{h^{2}} f ?(\eta)
\end{aligned}
$$

From (21) and (22) we get

$$
\frac{\mu}{h^{2}} f^{\prime \prime \prime}(\eta)-i \rho \omega f^{\prime} \quad(\eta)=c_{5}
$$

The arbitrary constant $\mathrm{c}$ is obtained as

$c_{5}=\frac{\mu}{h^{2}} f^{\prime \prime \prime}(0)$ since $f^{\prime}(0)=0$.

The pressure drop is given by

$p(x, \eta)-p(0,0)=k_{1}\left(\frac{u o}{a}-\frac{v_{2} x}{h}\right) x+\mu \frac{v_{2}}{h^{2}} f^{\prime}(\eta)-i \rho w v_{2} \int_{0}^{\eta} f(\eta) d \eta$

\section{DISCUSSION:}

The numerical values of $u$ ( $x$-direction) and $v$ ( $y$-direction) velocity profiles have been calculated for different values of $x$ and $y$. Itis assumed that $0 \leq x \leq 4$ and $0 \leq y \leq 10$.



Fig 1 (a):Axial velocity profiles for $\mathrm{x}=0, \mathrm{~h}=10, \mathrm{uo}=0.5$ for different values of $w t$

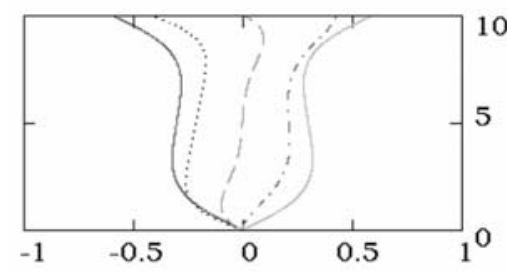

Fig 1 (b): Axial velocity profiles for $x=2, h=10$, $\mathrm{uo}=0.5$ for different values of wt . 


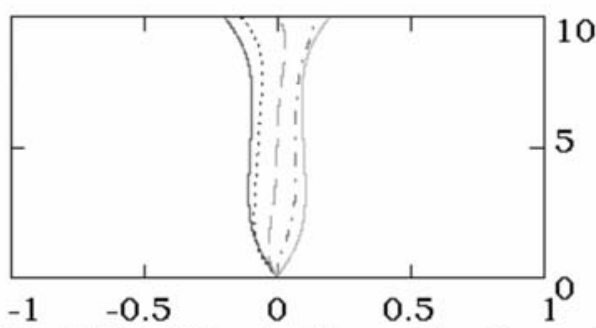

Fig 1(c):Axial velocity profiles for $\mathrm{x}=4$, $h=10, u o=0.5$ for different values of wt.

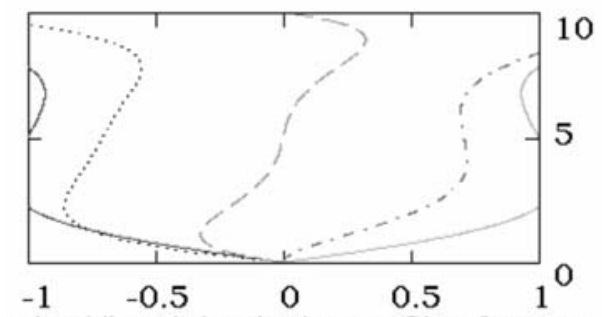

Fig1(d): Axial velocity profiles for $\mathrm{x}=0$ $h=10$,uo $=1.0$ for different values of wt.

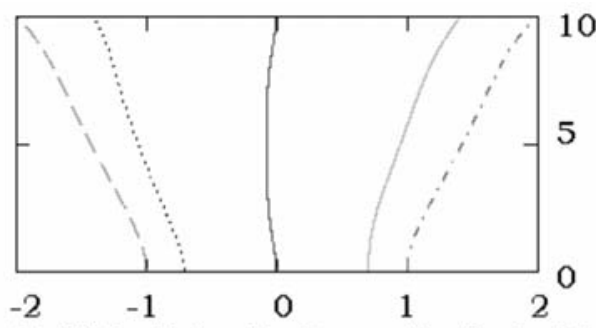

Fig(2): Radial velocity profile for $\mathrm{h}=10$, $a=1 / 2, v 2=2$.

Figures $1(a), 1(b)$ and $1(c)$ are the axial velocity profiles at different cross sections of the channel namely at $x=0, x=2$ and $x=4$ when the average entrance velocity is 0.5 . The magnitude of the axial velocity decreases as $x$ increases from 0 to 4 . The figure 1 (d) represents the axial velocity profiles of $u$ at $x=0, h=10$ when the inlet velocity is increased to 1 from 0.5 . It is clearly seen that the magnitudes of the axial velocity $u$ are more when the value of the inlet velocity is increased. It is also seen from the figure 2 that the radial velocity vanishes for $w t=d^{\pi} d d$ and the radial velocity profiles are non-linear for the other values of $w t$.

\section{CONCLUSION:}

In the above analysis a class of solutions of the unsteady stokes flow of viscous fluid between two parallel porous plates is presented, when there exists variable suction or injection at the walls. The authors presumes that the result presented here add one more class of exact solution to that of a few presently available in literature. The result for the axial velocity obtained here reduces to the result for the axial velocity in the case of laminar flow between parallel plates. (i.e., when $v=0$ ).

\section{NOMENCLATURE:}

$\begin{array}{ll}\mathrm{a}, \mathrm{v}_{1}, \mathrm{v}_{2} & \text { Constants } \\ \mathrm{C}_{1}, \mathrm{c}_{2}, \mathrm{c}_{3}, \mathrm{c}_{4} & \text { Constants } \\ \mathrm{C}_{5}, \mathrm{~K}_{1} & \text { Arbitrary constant } \\ \mathrm{u}_{0} & \text { Average entrance velocity } \\ \mathrm{h} & \text { Height of the channel } \\ \vec{q} & \text { Velocity vector } \\ \mathrm{p} & \text { Pressure } \\ \mathrm{u}(\mathrm{x}, \mathrm{y}) & \text { Axial component of velocity } \\ \mathrm{v}(\mathrm{x}, \mathrm{y}) & \text { Radial component of velocity } \\ (\mathrm{x}, \mathrm{y}) & \text { Stream function } \\ \mathrm{f}(\mathrm{\eta}) & \text { Function of } \eta \\ \eta=y / h & \text { Dimension less distance }\end{array}$

$\omega \quad$ Frequency

t

Time

\section{GREEK SYMBOLS:}

$\mu \quad$ Viscosity

$\rho \quad$ Density

$\Gamma \quad$ Kinematic Viscosity

$\alpha^{2} \quad \frac{i \rho \omega}{\mu}$

\section{REFERENCES}

[1] Berman.A.S.(1953)

Laminar flow in channels with porous walls

J.Appl. Phys., 24, p.1232

[2] Sellars.J.R.(1955)

Laminar flow in channels with porous walls at high suction Reynolds number.

J. Appl. Phys., 26, p.489

[3] Yuan.S.W.(1956)

Further investigations of laminar flow in channels with porous walls.

J.Appl. Phys., 27, p.267

[4] Terill.R.M.(1964)

The Aeronautical Quart.,15, p.299 
[5] Terill.R.M. and Shreshta.G.M.(1965) Laminar flow through parallel and uniformly porous walls of different

permeability. ZAMP. 16, p.470

[6] D.G.Drake(1965)

Quart.J.Mech.Appl.Math.18, p.1

[7] I.C.Bagchi (1966) Ind.J.Mech.Math.4, p.2
[8] F.M.White(1991)

Viscous Fluid Flow,Second edition, Mcgraw-Hill Company New York.

[9] R.L.Panton(1996) Incompressible Flow,Second edition, J.Wiley, New York.

[10] P.A.Long well(1966)

Mechanics of Fluid Flow, McGraw-Hill Company, New York. 